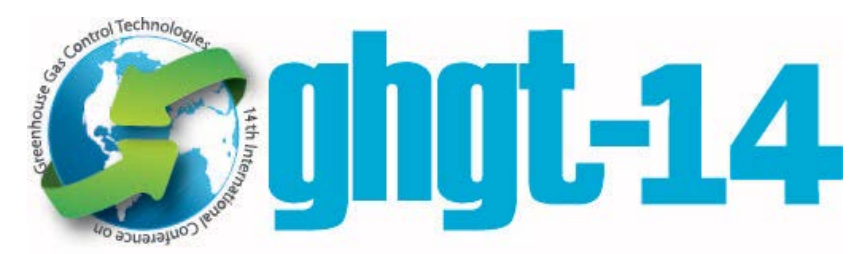

14th International Conference on Greenhouse Gas Control Technologies, GHGT-14 $21^{\text {st }}-25^{\text {th }}$ October 2018, Melbourne, Australia

\title{
From Residual Steel gases to Methanol: The FReSMe project
}

\author{
D. Bonalumi ${ }^{a^{*}}$, G.Manzolini ${ }^{\text {a }}$, J. Vente ${ }^{\mathrm{b}}$, H.A.J. van Dijk ${ }^{\mathrm{b}}$, L. Hooeyc, Emeric Sarron ${ }^{\mathrm{d}}$ \\ ${ }^{a}$ Politecnico di Milano, Dep. of Energy Via Lambruschini, 420156 Milano, Italy \\ ${ }^{b}$ TNO, Westerduinweg 3, 1755 LE Petten, The Netherlands \\ c Swerea Mefos, Aronstorpsvägen 1, 97437 Luleå, Sweden \\ ${ }^{d}$ Carbon Recycling Internationa, Holtasmári 1, 201 Kópavogur, Icelandl,
}

\begin{abstract}
With several carbon capture and storage (CCS) pilot and demonstration units deployed worldwide, the complementary approach of carbon dioxide use to increase the unitization of fossil carbon is being suggested. Conversion of $\mathrm{CO}_{2}$ can lead to useful product. Methanol is a high volume platform chemical of universal use in chemical industry as well as applicable for fueling internal combustion engines. FReSMe project will demonstrate the production of Methanol (MeOH) using as feedstock $\mathrm{CO}_{2}$ from Blast Furnace Gas (BFG). This paper presents the process modelling of the FReSMe concept and compares it with a standard methanol synthesis plant with Natural Gas as feedstock. The production of methanol based on the concept proposed in the FReSMe project requires higher energy, but lead to a reduction of about $1036 \mathrm{~kg}_{\mathrm{CO} 2} / \mathrm{t}_{\mathrm{MeOH}}$.
\end{abstract}

Keywords: CCUS; CO2 utilization; Methanol; SEWGS; Blast furnace gases, CO2 footprint

\section{Introduction}

With several carbon capture and storage (CCS) pilot and demonstration units deployed worldwide (the largest one being the Boundary Dam Integrated Carbon Capture and Storage Project [1]), the complementary approach of carbon dioxide use to increase the unitization of fossil carbon is being suggested. In these terms, the current most pressing challenge consist of:

(i) the utilization of the captured $\mathrm{CO}_{2}(\mathrm{CCU})$ as a feedstock for the process industry on one hand,

(ii) the production of high-volume value-added products as a commodity chemical, with a reduced carbon footprint

Chemical conversions of $\mathrm{CO}_{2}$ can be performed at moderately high temperatures and pressures by taking advantage of knowledge already known in the (petro)-chemical industry. A central challenge here can be found in the utilization of low-cost low-carbon electricity that will be intermittently available for the production of hydrogen.

Methanol is a high volume platform chemical of universal use in chemical industry as well as applicable for fueling internal combustion engines. As such, it provides a promising pathway for the large scale re-use of $\mathrm{CO}_{2}$ to decarbonize the transportation and chemical sectors in Europe and decrease the dependence on fossil fuel imports. Production of

\footnotetext{
${ }^{*}$ Corresponding author. Tel.: +39-02-23993817; fax: +39-02-23993913.

E-mail address: davide.bonalumi@polimi.it
} 
methanol from $\mathrm{CO}_{2}$ offers the unique combination of scale, efficiency and economic value necessary to achieve largescale carbon reduction targets. Currently, a first demonstration plant is being operated by CRI in Iceland using $\mathrm{CO}_{2}$ originating from geothermal sources [2], and a pilot is being constructed in Germany on the basis of $\mathrm{CO}_{2}$ coming from a coal fired power plant in MefCO2 project [3].

In this context, the FReSMe project will demonstrate the production of Methanol (MeOH) using as $\mathrm{CO}_{2}$ from blast furnace gases (BFG) in the iron and steel industry. The sector is responsible for $7 \%$ of world $\mathrm{CO}_{2}$ emissions. BFG consist of $\sim 50 \% \mathrm{~N}_{2}$ and equal parts of $\mathrm{CO}$ and $\mathrm{CO}_{2}$ with further minor amounts of $\mathrm{H}_{2}$. The energetic content is commonly used for local heat and power production, but can also be converted into a highly versatile fuel and chemical, increasing the utilization the fossil fuel which is necessarily used in this sector.

Methanol is a high volume platform chemical of universal use in chemical industry as well as applicable for fueling internal combustion engines. As such it provides a promising pathway for the large scale re-use of $\mathrm{CO}_{2}$ to decarbonize the transportation and chemical sectors in Europe and decrease the dependence on fossil fuel imports. Production of methanol from $\mathrm{CO}_{2}$ offers the unique combination of scale, efficiency and economic value necessary to achieve large-scale carbon reduction targets.

In this paper, we will present the process modelling of the FReSMe concept and compares it with a standard methanol synthesis plant with Natural Gas as feedstock.

\section{FReSMe Project}

FReSMe project [4] will demonstrate the production of Methanol (MeOH) using as feedstock $\mathrm{CO}_{2}$ from Blast Furnace Gas (BFG) at TRL6 under industrially relevant process conditions and using all the relevant sequential process steps simultaneously. This will be achieved by a consortium consisting of the whole value chain from technology developer and provider, material manufacturers, through engineering to end users. Additionally, the flexible concept will allow supplemental $\mathrm{MeOH}$ production with $\mathrm{H}_{2}$ derived from an electrolyser and provides a route to commercialization for both near-term and future-term implementations that can scale with the increasing availability of low carbon $\mathrm{H}_{2}$.

FReSMe joins facilities and expertise from two existing pilot sites which are co-funded by the Horizon 2020 program; BFG upgrading equipment available from the STEPWISE project; and $\mathrm{MeOH}$ Synthesis equipment available from the MefCO2 project. Today's integrated steel mill is normally a net electricity exporter; by coupling these two highly efficient systems together, the excess energy that is normally only for power production, can be used for the production of a highly versatile fuel and chemical, increasing the utilization of the $\mathrm{CO}_{2}$ and the fossil fuel from which it is necessarily derived.

The pilot testing of FReSME will be implemented at one of the world's few facilities that is specifically designed to supply up to $2500 \mathrm{~m}^{3} / \mathrm{hr}$ BFG from an integrated iron and steel mill to an experimental hall capable of housing large pilot installations, to produce in excess of $50 \mathrm{~kg}$ methanol per hour, an appropriate scale for TRL6. Existing processes will be optimized towards the most effective $\mathrm{MeOH}$ production process at the lowest cost and smallest energy penalty for the steel industry.

The FReSMe concept takes advantage of the Sorption Enhanced Water Gas Shift (SEWGS) [5] technology for converting the $\mathrm{CO}$ with steam into $\mathrm{CO}_{2}$ and $\mathrm{H}_{2}$ and simultaneously separating the $\mathrm{CO}_{2}$ from the hydrogen in the steel off-gases.

Methanol is produced in a highly-flexible unit designed (i) for testing in an operation environment subject to variation due to the availability of fuel to variation due to the availability of feedstock and changes in feedstock composition and (ii) for producing 1 ton/day methanol at fuel grade standard suitable for use in end-user demonstration.

Because of the high $\mathrm{CO}_{2}$ to $\mathrm{H}_{2}$ ratio in the steel-plant off gases, additional $\mathrm{H}_{2}$ produced from an electrolizer will be used. In an alternative implementation the excess $\mathrm{CO}_{2}$ can be sequestrated. The concept is depicted in Fig. 1 . 


\begin{tabular}{|ll|}
\hline Nomenclature & \\
CCS & Carbon Capture and storage \\
CCUS & Carbon Capture Utilization and storage \\
BFG & Blast Furnace Gases \\
MeOH & Methanol \\
SEWGS & Sorption Enhanced Water Gas Shift \\
\hline
\end{tabular}

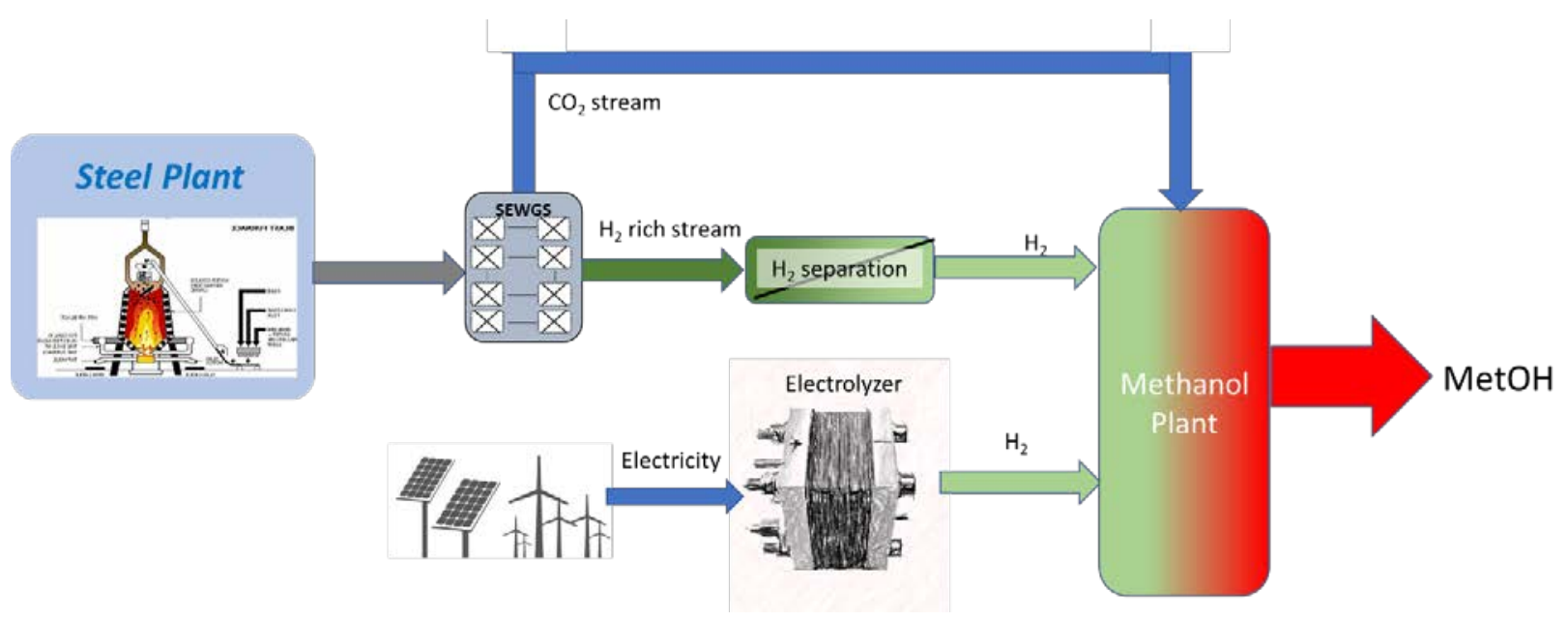

Fig. 1 FReSMe concept

\section{Processes Simulations}

The plants are simulated with the software Aspen Plus. For the standard synthesis of MeOH three main steps are considered: (i) gas pre-treatments, (ii) natural gas reforming, (iii) methanol production and purification. Energy and mass balances are calculated and detailed. These steps are represented in Fig. 2.

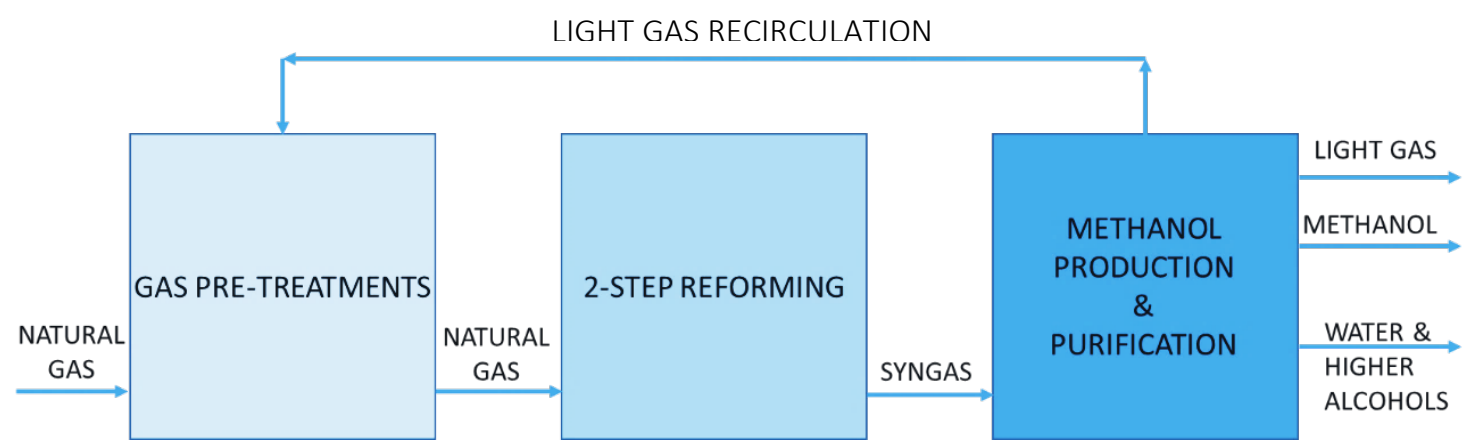

Fig. 2 Flowsheet of methanol production from natural gas

For the synthesis with the gas coming from the SEWGS the main steps are two: (i) gas pre-treatments, (ii) methanol production and purification. The gas pre-treatments are not the same.

The first and second sections represented in Figure 2 are simulated with the Peng-Robinson equation of state, while the third with the NRTL-RK (Non-Random-Two-Liquid/Redlich-Kwong) thermodynamic model. 


\subsection{Methanol production with natural gas}

The gas pre-treatment section is shown in Fig. 3. Natural gas is fed to the plant and is split into two streams. A small fraction is burnt in a combustion chamber and the flue gas is cooled down to $700^{\circ} \mathrm{C}$. Part of the heat is exchanged with the natural gas that is compressed.

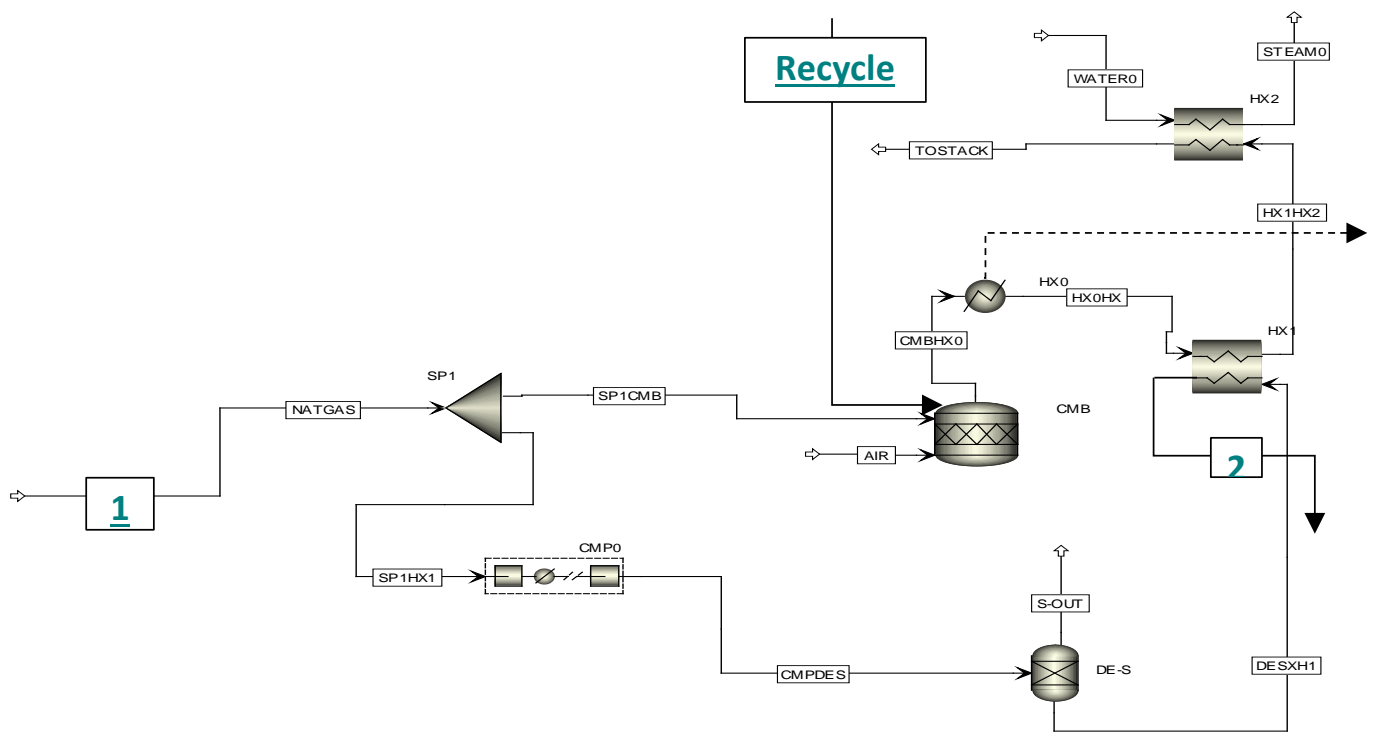

Fig. 3 Gas pre-treatment step for methanol production with natural gas. Stream "1" indicates the natural gas fed to the plant; stream "2" indicates the compressed natural gas fed to the pre-reformer.

The compressed gas enters into a pre-reformer where steam is added in order to obtain a steam to carbon ratio equal to 1.8. The pre-reformer works at temperature of $485^{\circ} \mathrm{C}$ and $30 \mathrm{bar}$. The pre-reformed gas enters in the first and second reformer: the first one has an equilibrium temperature of $694^{\circ} \mathrm{C}$ while the second reaches the temperature of $972^{\circ} \mathrm{C}$ due to the introduction of $\mathrm{O}_{2}$ at $95 \%$ that allows partial oxidation of the reactants and final methane conversion to hydrogen at high temperature. The reformed syngas is then cooled recovering heat at a useful temperature. The syngas is then compressed to be delivered to the methanol reactor. This step is shown in Fig. 4.

The methanol reactor converts hydrogen and carbon oxides to methanol. The reactor is a catalytic packed-bed type cooled (methanol reaction is exothermic) generating steam used for the reforming reaction. The reactor is simulated by specifying the reactions involved in the methanol reactor; they are reported in equation (1)-(4):

$$
\begin{aligned}
& \mathrm{CO}_{2}+3 \mathrm{H}_{2} \rightleftarrows \mathrm{CH}_{3} \mathrm{OH}+\mathrm{H}_{2} \mathrm{O} \\
& \mathrm{CO}+2 \mathrm{H}_{2} \rightleftarrows \mathrm{CH}_{3} \mathrm{OH} \\
& \mathrm{CO}_{2}+4 \mathrm{H}_{2} \rightleftarrows \mathrm{CO}+\mathrm{H}_{2} \mathrm{O} \\
& 2 \mathrm{CO}+4 \mathrm{H}_{2} \rightleftarrows \mathrm{C}_{2} \mathrm{H}_{5} \mathrm{OH}+\mathrm{H}_{2} \mathrm{O}
\end{aligned}
$$

The main impurities of the $\mathrm{MeOH}$ are the gases dissolved in the liquid phase and the by-products such as higher alcohols and especially ethanol [6]. The products at the reactor outlet are flashed to separate the light gases from the liquid (raw methanol). The light gases are mainly recycled to the methanol reactor, while a small fraction is sent to a membrane separator that routes the $\mathrm{H}_{2}$ to the methanol reactor and the remaining part to the combustion chamber. The raw methanol is processed in a first distillation column designed to separate the residual light gases from the liquid phase. The second column purifies the methanol at Grade AA, which is obtained from the top of the column. The first and second columns' pressure at the bottom is respectively around 2 bar and 1.5 bar. The second column is the one 
with the highest heat duty, because of the high reflux ratio. Key operating parameters are given in Tab. 1 and main stream compositions in Tab. 2. Tab. 5 summarizes the overall $\mathrm{CO}_{2}$ and energy performance for methanol production.

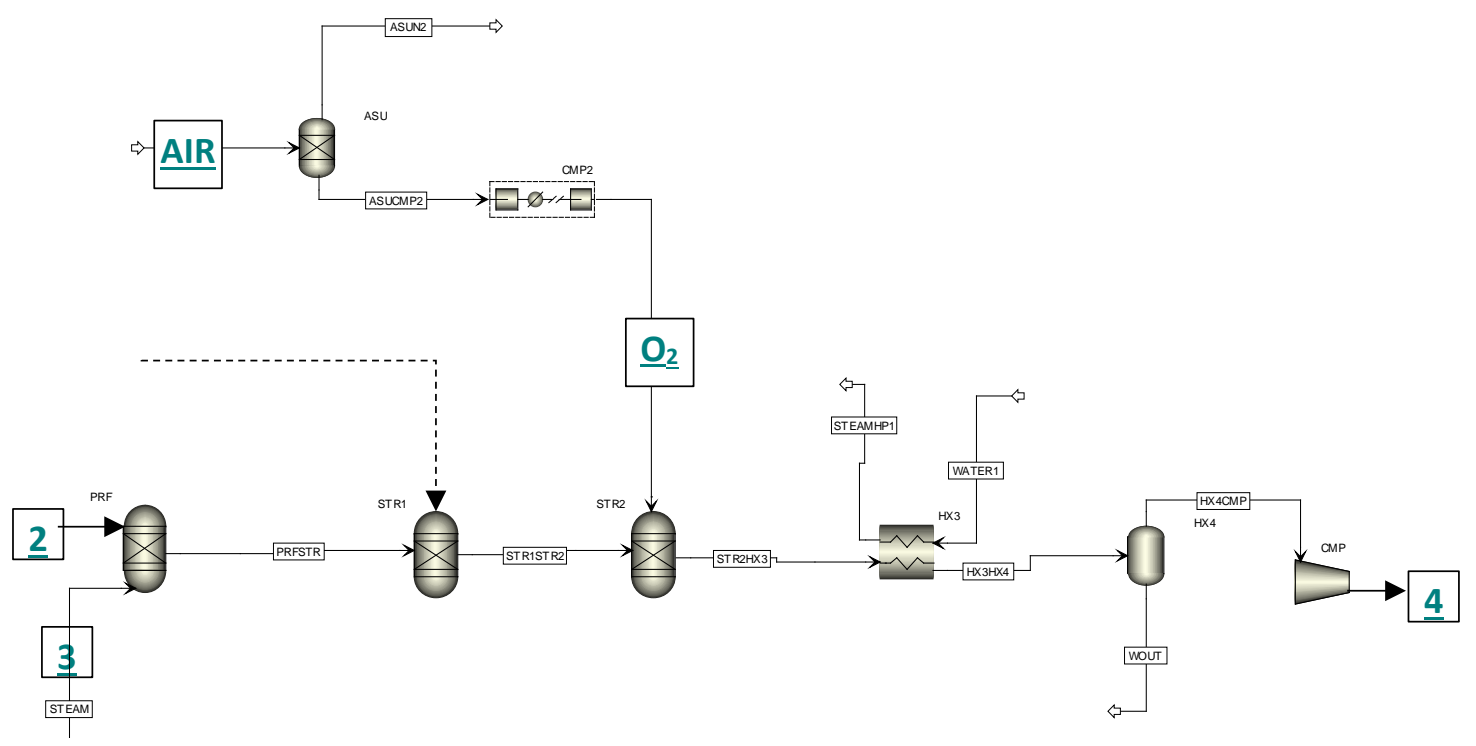

Fig. 4 2-steps reforming step. Stream "2" indicates the compressed natural gas; stream " 3 " indicates the steam fed to the plant; stream " 4 " indicates the compressed syngas fed to the methanol reactor.

Tab. 1 Key operating parameters of methanol plant

\begin{tabular}{|c|c|}
\hline S/C at reformed inlet & 1.8 \\
\hline Process steam consumption & $1.09 \mathrm{t}_{\mathrm{H} 2 \mathrm{O}} / \mathrm{t}_{\mathrm{CH} 3 \mathrm{OH}}$ \\
\hline Overall Natural Gas consumption & $0.65 \mathrm{t}_{\mathrm{NG}} / \mathrm{t}_{\mathrm{CH} 3 \mathrm{OH}}$ \\
\hline$\frac{\mathrm{H}_{2}-\mathrm{CO}_{2}}{\mathrm{CO}+\mathrm{CO}_{2}}$ at methanol reactor inlet & 3.59 \\
\hline Availability & $98 \%$ \\
\hline Nominal capacity for standard plant & $2500 \mathrm{t} / \mathrm{d} \mathrm{CH}_{3} \mathrm{OH}$ \\
\hline & \\
\hline
\end{tabular}

Tab. 2 Thermodynamic conditions, flowrates and compositions of the main streams shown in Fig. 3, Fig. 4, Fig. 5. *includes NG to distillation, not shown in Fig. 5

\begin{tabular}{ccccccccccccccccc}
\hline point & $\mathbf{T}$ & $\mathbf{p}$ & $\mathbf{~ m}$ & \multicolumn{10}{c}{ Molar composition (\%) } \\
\hline & ${ }^{\circ} \mathbf{C}$ & $\mathbf{b a r}$ & $\mathbf{~ k g} / \mathbf{s}$ & $\mathbf{C H}_{\mathbf{4}}$ & $\mathbf{C}_{\mathbf{2}} \mathbf{H}_{\mathbf{6}}$ & $\mathbf{C}_{\mathbf{3}} \mathbf{H}_{\mathbf{8}}$ & $\mathbf{C}_{\mathbf{4}} \mathbf{H}_{\mathbf{1 0}}$ & $\mathbf{C}_{\mathbf{5}} \mathbf{H}_{\mathbf{1 2}}$ & $\mathbf{C O}_{2}$ & $\mathbf{C O}$ & $\mathbf{C H}_{\mathbf{3}} \mathbf{O H}$ & $\mathbf{C}_{2} \mathbf{H}_{\mathbf{5}} \mathbf{O H}$ & $\mathbf{H}_{\mathbf{2}} \mathbf{O}$ & $\mathbf{H}_{2}$ & $\mathbf{N}_{\mathbf{2}}$ \\
\hline $\mathbf{1}^{*}$ & 20.0 & 1.00 & 18.87 & 83.9 & 9.2 & 3.3 & 1.2 & 0.2 & 1.8 & 0 & 0 & 0 & 0 & 0 & 0.4 \\
$\mathbf{2}$ & 716.1 & 30.00 & 15.87 & 83.9 & 9.2 & 3.3 & 1.2 & 0.2 & 1.8 & 0 & 0 & 0 & 0 & 0 & 0.4 \\
$\mathbf{3}$ & 450.0 & 50.00 & 31.72 & 0 & 0 & 0 & 0 & 0 & 0 & 0 & 0 & 0 & 100 & 0 & 0 \\
$\mathbf{4}$ & 51.3 & 80.00 & 80.25 & 32.8 & 0 & 0 & 0 & 0 & 6.9 & 0.8 & 0.9 & 0 & 0.1 & 55.3 & 3.1 \\
$\mathbf{5}$ & 50.0 & 79.00 & 35.15 & 1 & 0 & 0 & 0 & 0 & 1.5 & 0 & 75.1 & 0.2 & 22 & 0.2 & 0 \\
$\mathbf{6}$ & 50.0 & 79.00 & 81.06 & 32.8 & 0 & 0 & 0 & 0 & 6.9 & 0.8 & 0.9 & 0 & 0.1 & 55.3 & 3.1 \\
$\mathbf{7}$ & 30.4 & 1.30 & 1.01 & 36.2 & 0 & 0 & 0 & 0 & 42.3 & 0.2 & 13.1 & 0 & 0.7 & 6 & 1.5 \\
$\mathbf{8}$ & 77.9 & 1.57 & 29.09 & 0 & 0 & 0 & 0 & 0 & 0.3 & 0 & 76.9 & 0.2 & 22.6 & 0 & 0 \\
\hline
\end{tabular}




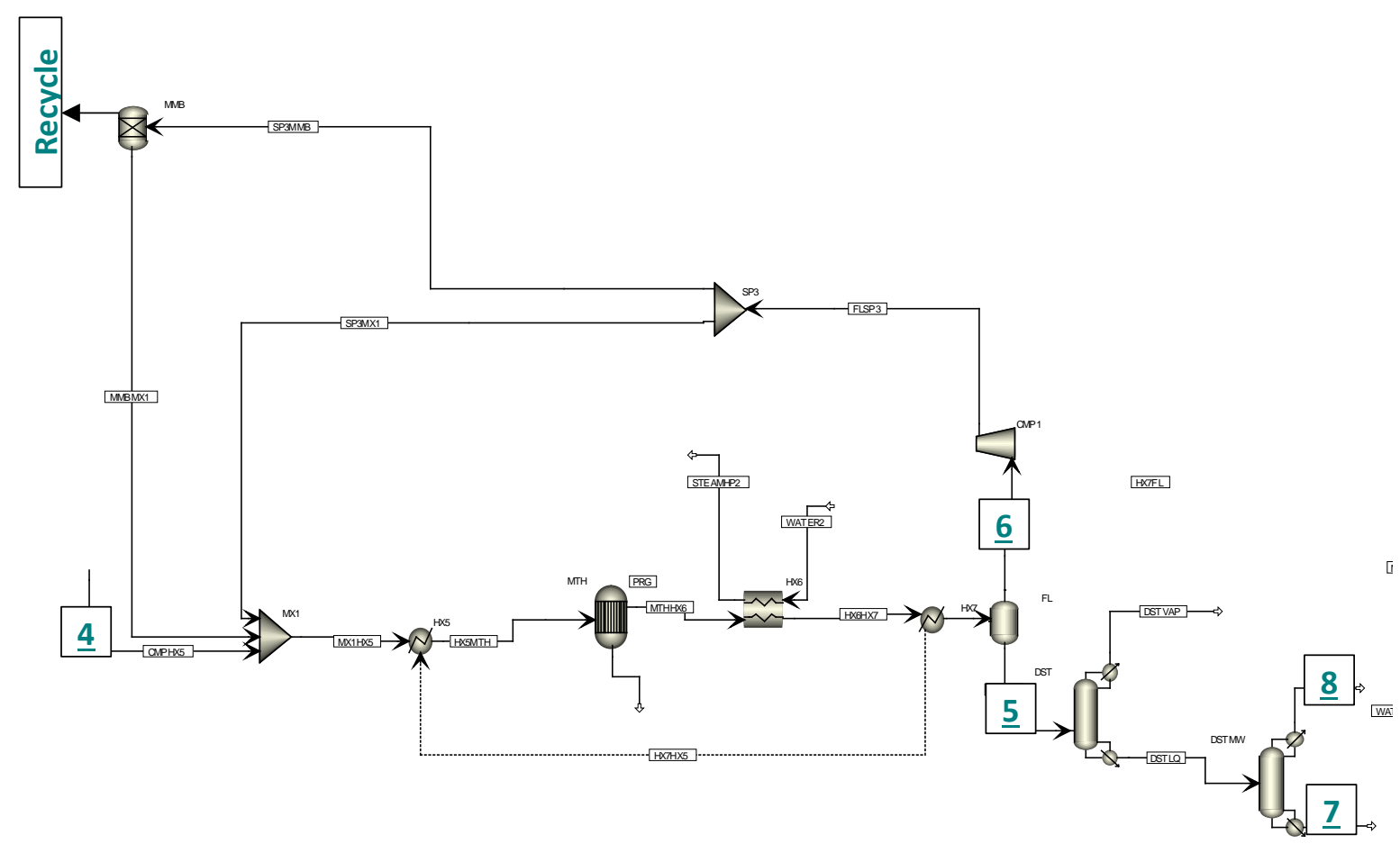

Fig. 5 methanol production and purification step. Stream " 4 " indicates the compressed syngas; stream " 5 " indicates the raw methanol production; stream " 6 " indicates the light gases separated from the raw methanol production; stream "7" indicates the high-boiling component of the raw methanol; stream " 8 " indicates the grade AA methanol production.

\subsection{Methanol production with SEWGS gases}

The FReSMe plant accounts for the reaction of the $\mathrm{CO}_{2}$ and $\mathrm{H}_{2}$ separated from the BFG, by means of SEWGS technology [5], additional $\mathrm{H}_{2}$ is obtained by the adoption of an electrolyzer. SEWGS, which stands for Sorption Enhanced Water Gas Shift reactor, works at high pressure $\left(20 \div 30\right.$ bar) and combines the shift reaction with the $\mathrm{CO}_{2}$ adsorption. The sorbent regeneration is performed by reducing the reactor pressure to low pressure. After the SEWGS two main streams are sent to the plant for the methanol production. One is rich in $\mathrm{H}_{2}$ and the other is rich in $\mathrm{CO}_{2}$. The detailed compositions are reported in reported in Tab. 3.

In this work, the amount of the gases available from the blast furnace of the steel plant are the one considered in the STEPWISE Project. Their composition is obtained by applying the SEWGS technology.

Tab. 3 Composition of the gases fed to the plant for the production of methanol

\begin{tabular}{ccccccccc}
\hline name & $\mathrm{T}\left({ }^{\circ} \mathrm{C}\right)$ & $\mathrm{P}(\mathrm{bar})$ & $\mathrm{M}(\mathrm{kg} / \mathrm{s})$ & $\mathrm{CO}, \%$ & $\mathrm{CO}_{2}, \%$ & $\mathrm{H}_{2}, \%$ & $\mathrm{H}_{2} \mathrm{O}, \%$ & $\mathrm{~N}_{2}, \%$ \\
\hline $\mathrm{H}_{2}$-rich & 430 & 24 & 89.9 & 2.2 & 3.95 & 33.68 & 4.64 & 55.53 \\
$\mathrm{CO}_{2}$-rich & 411.2 & 1.2 & 152.8 & 0 & 48.26 & 0 & 50.57 & 1.17 \\
\hline
\end{tabular}

The scheme of plant for methanol production with the gases coming from the steel plant is shown in Fig. 6. 


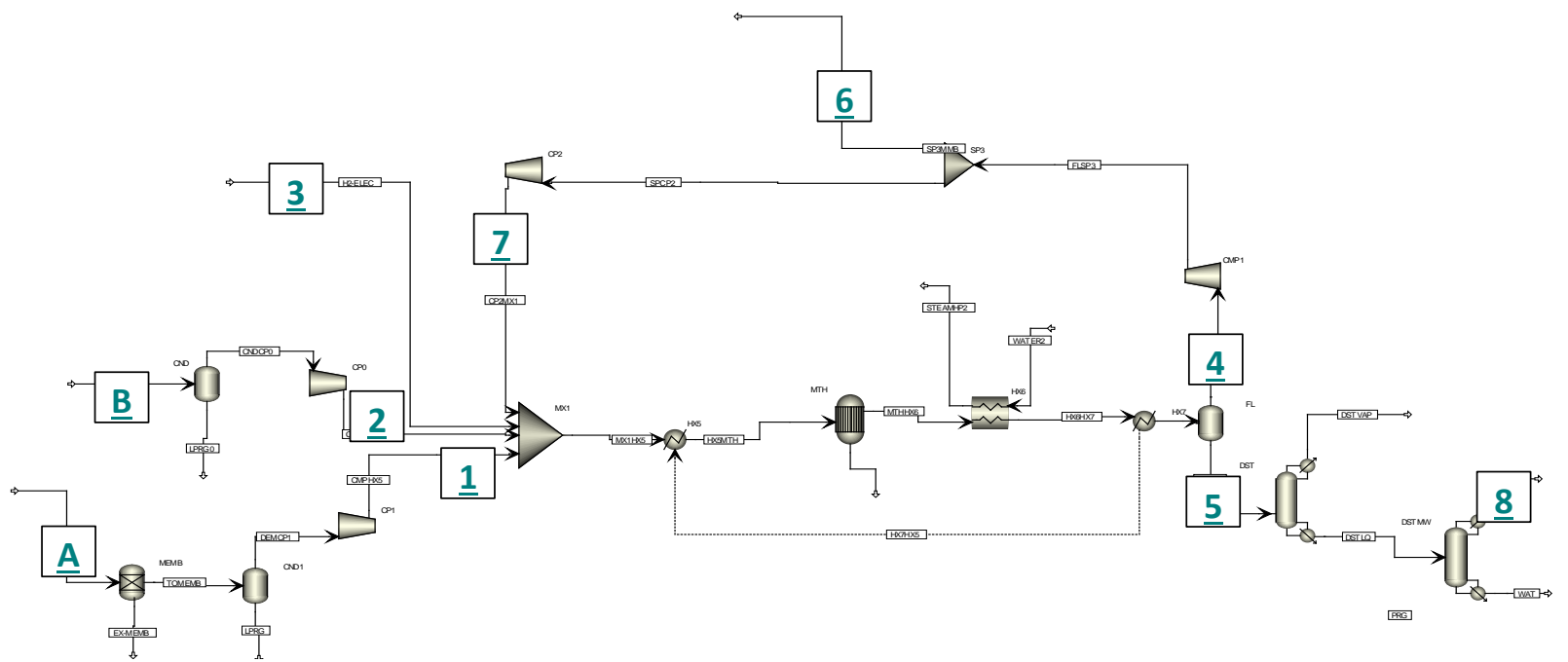

Fig. 6 Scheme of plant for methanol production with gas from SEWGS. Stream "A" indicates the stream H2-rich fed to the plant, while the " $\mathrm{B}$ " indicates the $\mathrm{CO}_{2}$-rich. The stream " 1 " indicates the stream rich in $\mathrm{H}_{2}$ that is sent the methanol reactor; the stream " 2 " indicates the stream rich in $\mathrm{CO}_{2}$ that is sent to the methanol reactor. The stream " 3 " indicates the $\mathrm{H}_{2}$ added with an electrolyzer; stream " 4 " indicates the light gases separated from the raw methanol production; stream " 5 " indicates the raw methanol production; stream "6" indicates the vented light gases; stream " 7 " indicates the high-boiling component of the raw methanol; stream "8" indicates the grade AA methanol production.

The stream $\mathrm{H}_{2}$-rich is fed to the methanol plant and passes through a membrane to increase the $\mathrm{H}_{2}$ concentration by separating the $\mathrm{N}_{2}$ that is purged (the high nitrogen content comes from the BFG). The concentrated $\mathrm{H}_{2}$ is cooled and a liquid purge is separated before to compress the purified stream. In parallel, the stream $\mathrm{CO}_{2}$-rich is cooled to eliminate the water before the stream compression. The BFG has a very high carbon content with respect to the hydrogen meaning that the amount of $\mathrm{H}_{2}$ coming from the SEWGS is less than stoichiometric with respect to Eq. (1). To reach the stoichiometric value, there are two options: the first one consists of supplying additional $\mathrm{H}_{2}$ produced with an electrolyzer, while in the second case, not considered in this work, part of the $\mathrm{CO}_{2}$ is captured and stored. The main rationale behind this concept is the utilization of green electricity produced from renewable sources- The energy consumption due to the adoption of the electrolyzer is evaluated to be equal to $5 \mathrm{kWh} / \mathrm{Nm}^{3}$ [7]. All these feeding streams are mixed in the methanol reactor. After the mixer, the scheme of plant is the same as the case fed with the natural gas. The main streams composition and thermodynamic conditions are reported in Tab. 4.

Tab. 4 Thermodynamic conditions, flowrates and compositions of the main streams shown in Fig. 6.

\begin{tabular}{cccccccccccccccc}
\hline point & $\mathbf{T}$ & $\mathbf{p}$ & $\mathbf{~ m}$ & \multicolumn{10}{c}{ Molar composition } \\
\hline & ${ }^{\circ} \mathbf{C}$ & $\mathbf{b a r}$ & $\mathbf{~ k g} / \mathbf{s}$ & $\mathbf{C H}_{\mathbf{4}}$ & $\mathbf{C}_{2} \mathbf{H}_{\mathbf{6}}$ & $\mathbf{C}_{3} \mathbf{H}_{\mathbf{8}}$ & $\mathbf{C}_{\mathbf{4}} \mathbf{H}_{\mathbf{1 0}}$ & $\mathbf{C}_{5} \mathbf{H}_{\mathbf{1 2}}$ & $\mathbf{C O}_{2}$ & $\mathbf{C O}$ & $\mathbf{C H}_{\mathbf{3}} \mathbf{O H}$ & $\mathbf{C}_{2} \mathbf{H}_{\mathbf{5}} \mathbf{O H}$ & $\mathbf{H}_{\mathbf{2}} \mathbf{O}$ & $\mathbf{H}_{\mathbf{2}}$ & $\mathbf{N}_{\mathbf{2}}$ \\
\hline $\mathbf{1}$ & 207.9 & 80.0 & 14.2 & 0 & 0 & 0 & 0 & 0 & 9.9 & 5.5 & 0 & 0 & 0.5 & 84.2 & 0 \\
$\mathbf{2}$ & 537.3 & 80.0 & 152.8 & 0 & 0 & 0 & 0 & 0 & 97.6 & 0 & 0 & 0 & 0 & 0 & 2.4 \\
$\mathbf{3}$ & 50.0 & 80.0 & 18.6 & 0 & 0 & 0 & 0 & 0 & 0 & 0 & 0 & 0 & 0 & 100 & 0 \\
$\mathbf{4}$ & 50.0 & 79.0 & 764.2 & 0 & 0 & 0 & 0 & 0 & 17.9 & 5 & 0.6 & 0 & 0.1 & 69.6 & 6.8 \\
$\mathbf{5}$ & 50.0 & 79.0 & 170.4 & 0 & 0 & 0 & 0 & 0 & 1.4 & 0 & 49.5 & 0.1 & 49.1 & 0.1 & 0 \\
$\mathbf{6}$ & 50.0 & 79.0 & 15.3 & 0 & 0 & 0 & 0 & 0 & 17.9 & 5 & 0.6 & 0 & 0.1 & 69.6 & 6.8 \\
$\mathbf{7}$ & 51.4 & 80.0 & 748.9 & 0 & 0 & 0 & 0 & 0 & 17.9 & 5 & 0.6 & 0 & 0.1 & 69.6 & 6.8 \\
$\mathbf{8}$ & 64.3 & 1.0 & 107.1 & 0 & 0 & 0 & 0 & 0 & 0.3 & 0 & 99.4 & 0 & 0.2 & 0 & 0 \\
\hline
\end{tabular}




\section{Results and Discussions}

Some performance indexes are defined to evaluate the system performance: specific consumption of feedstock, purity, specific energy demand and specific $\mathrm{CO}_{2}$ emissions.

The specific consumption of feedstock is referred to the production of one ton of methanol. It is defined for the natural gas and for the electricity:

$$
\begin{gathered}
\text { specific consumption of natural gas }=\frac{\text { mass of natural gas }[\text { ton }]}{\text { mass of produced } \mathrm{MeOH}[\text { ton }]} \\
\text { specific consumption of electricity }=\frac{\text { enenergy }[\mathrm{kWh}]}{\text { mass of produced } \mathrm{MeOH}[\text { ton }]} \\
\text { Purity }=\frac{\text { mass of pure } \mathrm{MeOH}[\mathrm{kg}]}{\text { mass of product obtained from the light components distillation }[\text { ton }]}
\end{gathered}
$$

The specific energy demand is defined accounting both natural gas and electricity which is reported to the primary energy with a conversion factor of $50 \%$ :

$$
\text { Specific energy demand }=\frac{\text { energy contained in the consumed feedstock }[G J]}{\text { mass of produced } \mathrm{MeOH}[\text { ton }]}
$$

The specific $\mathrm{CO}_{2}$ emissions are defined for the natural and for the electricity with an emission factor of emission factor $460 \mathrm{~g} / \mathrm{kWh}$ :

$$
\text { Specif } \mathrm{CO}_{2} \text { emission }=\frac{\text { mass of } \mathrm{CO}_{2} \text { contanined in the consumed feeedstock }[\mathrm{kg}]}{\text { mass of product obtained from the light components distillation }[\text { ton }]}
$$

The results are reported in Tab. 5 for the case with Natural Gas as feedstock, while for the case studied with the concept proposed in the FReSMe Project the results are reported in Tab. 6.

Tab. 5 Summary of energy balance and $\mathrm{CO}_{2}$ emissions for the plant fed with Natural Gas

\begin{tabular}{|c|c|c|c|c|c|c|}
\hline & \multicolumn{2}{|c|}{ Specific consumption } & \multicolumn{2}{|c|}{ Specific energy demand } & \multicolumn{2}{c|}{ Specific $\mathrm{CO}_{2}$ emission } \\
\hline Natural gas & 0.65 & $\mathrm{t} \mathrm{NG/t} \mathrm{MeOH}$ & 30.40 & $\mathrm{GJ} / \mathrm{t} \mathrm{MeOH}$ & 1759.9 & $\mathrm{~kg} \mathrm{CO}_{2} / \mathrm{t} \mathrm{MeOH}$ \\
\hline Electricity & 275.3 & $\mathrm{kWh} / \mathrm{t} \mathrm{MeOH}$ & 2.48 & $\mathrm{GJ} / \mathrm{t} \mathrm{MeOH}$ & 126.6 & $\mathrm{~kg} \mathrm{CO}_{2} / \mathrm{t} \mathrm{MeOH}$ \\
\hline Pure MeOH (purity) & 994.5 & $\mathrm{~kg} / \mathrm{t} \mathrm{MeOH}$ & -19.83 & $\mathrm{GJ} / \mathrm{t} \mathrm{MeOH}$ & -1371.6 & $\mathrm{~kg} \mathrm{CO}_{2} / \mathrm{t} \mathrm{MeOH}$ \\
\hline Net per tonne MeOH & & & 13.05 & $\mathrm{GJ} / \mathrm{t} \mathrm{MeOH}$ & 515.0 & $\mathrm{~kg} \mathrm{CO}_{2} / \mathrm{t} \mathrm{MeOH}$ \\
\hline
\end{tabular}

For the conventional way for methanol production the total amount of energy required is about $13 \mathrm{GJ} / \mathrm{tMeOH}$ and the specific emission are about $515 \mathrm{~kg}_{\mathrm{CO} 2} / \mathrm{t}_{\mathrm{MeOH}}$. 
Tab. 6 Summary of energy balance and $\mathrm{CO}_{2}$ emissions for the plant fed with gas from SEWGS

\begin{tabular}{|c|c|c|c|c|c|c|}
\hline & \multicolumn{2}{|c|}{ Specific consumption } & \multicolumn{2}{c|}{ Specific energy demand } & \multicolumn{2}{|c|}{ Specif $\mathrm{CO}_{2}$ emission } \\
\hline Natural gas & 0.08 & $\mathrm{t} \mathrm{NG/t} \mathrm{MeOH}$ & 3.61 & $\mathrm{GJ} / \mathrm{t} \mathrm{MeOH}$ & 209.2 & $\mathrm{~kg} \mathrm{CO}_{2} / \mathrm{t} \mathrm{MeOH}$ \\
\hline Electricity & 242.8 & $\mathrm{kWh} / \mathrm{t} \mathrm{MeOH}$ & 2.19 & $\mathrm{GJ} / \mathrm{t} \mathrm{MeOH}$ & 111.7 & $\mathrm{~kg} \mathrm{CO}_{2} / \mathrm{t} \mathrm{MeOH}$ \\
\hline $\begin{array}{c}\text { Electricity for the } \\
\text { electrolyzer }\end{array}$ & 10229.4 & $\mathrm{kWh} / \mathrm{t} \mathrm{MeOH}$ & 36.83 & $\mathrm{GJ} / \mathrm{t} \mathrm{MeOH}$ & 0 & $\mathrm{~kg} \mathrm{CO}_{2} / \mathrm{t} \mathrm{MeOH}$ \\
\hline $\begin{array}{c}\text { Pure MeOH (purity) } \\
\text { Net per tonne MeOH }\end{array}$ & 994.1 & $\mathrm{~kg} / \mathrm{t} \mathrm{MeOH}$ & -19.83 & $\mathrm{GJ} / \mathrm{t} \mathrm{MeOH}$ & -1371.6 & $\mathrm{~kg} \mathrm{CO}_{2} / \mathrm{t} \mathrm{MeOH}$ \\
\hline & & 22.79 & $\mathrm{GJ} / \mathrm{t} \mathrm{MeOH}$ & -1050.7 & $\mathrm{~kg} \mathrm{CO}_{2} / \mathrm{t} \mathrm{MeOH}$ \\
\hline
\end{tabular}

For the production of methanol with SEWGS gases (as FReSMe concept) the total amount of energy required is about $22.8 \mathrm{GJ} / \mathrm{tMeOH}$ and the specific emission computed in this way are negative: about $-1050 \mathrm{~kg} \mathrm{CO}_{2} / \mathrm{t}_{\mathrm{MeOH}}$. There is a small amount of natural gas, it is required for the distillation process.

These values shown that the energy impact of the new plant is higher than the conventional. The higher amount of the energy contribution is due to the electrolyzer. It is worth to highlight that, in the concept of the FReSMe project, the energy required for this component is obtained from renewable sources. The carbon footprint results lower with the new concept proposed in the project. A comparison with dimensionless values of the results, between the two ways of production, is shown in Fig. 7. The case with the conversion of the natural gas is taken as reference. It can be noted that the energy required from the FReSMe concept is about one and half time the energy required by the standard way, whereas the $\mathrm{CO}_{2}$ emitted for a ton of $\mathrm{MeOH}$ is the double for the standard way.

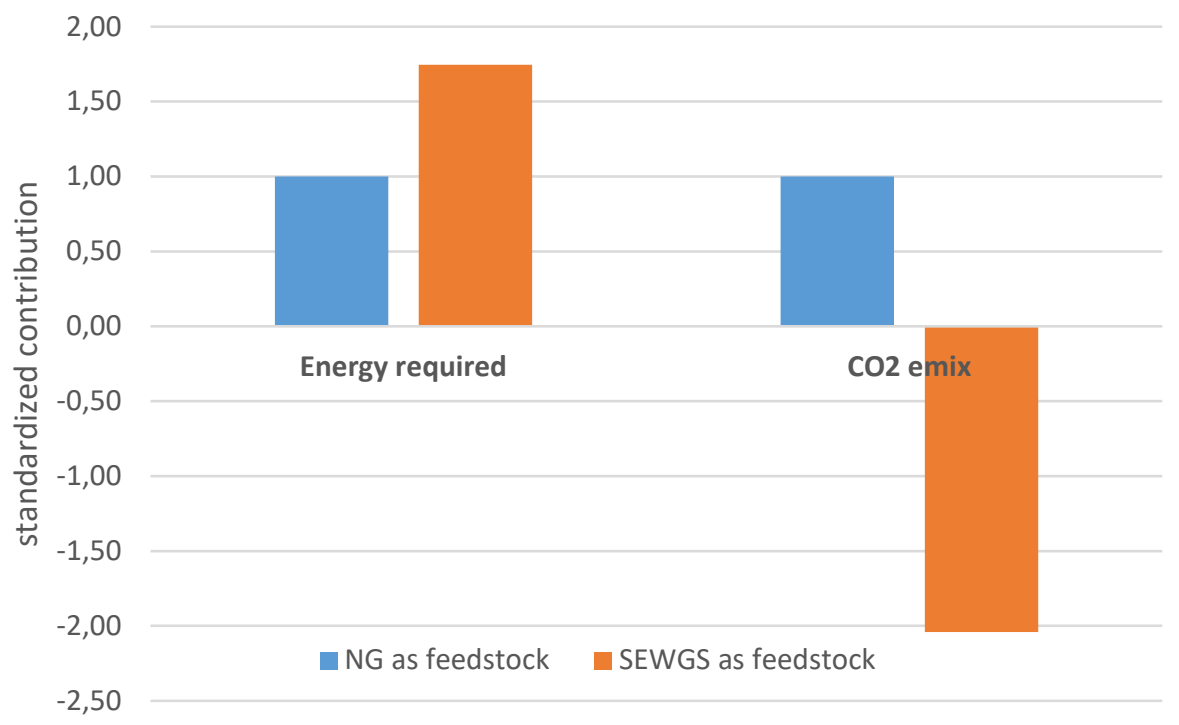

Fig. 7 Comparison of the energy impact for the two ways of methanol production and their CO2 footprint. 


\section{Conclusions and future works}

This work presented the production of Methanol (MeOH) using as feedstock $\mathrm{CO}_{2}$ from Blast Furnace Gas (BFG) which is investigated in the FReSMe project. Two ways for the production of methanol are studied: (i) a standard way with the conversion of Natural Gas used as reference and (ii) FReSMe's approach based on the conversion of SEWGS gases from a steel plant. The main results obtained from the two systems allow the evaluation of the $\mathrm{CO}_{2}$ emitted from the plants and thus the $\mathrm{CO}_{2}$ avoided with the innovative process.

It can be concluded that:

- The production of methanol based on the SEWGS gases is effective in the CCUS: a $\mathrm{CO}_{2}$ emission reduction of $1050 \mathrm{kgCO} / \mathrm{t}_{\mathrm{MeOH}}$ is assessed.

- The higher energy requirement for the methanol based on the SEWGS gases is due to the consumption required by the electrolyzer, where in the FReSMe approach, is supplied by renewable sources.

- High quality of methanol can be obtained

The carbon footprint is lower in the new concept because NG used in conventional production is replaced by a combination of: 1) $\mathrm{CO}_{2}$ that would otherwise have been emitted and 2) renewable electricity. Further analysis of environmental impact using LCA and overall techno-economics will be conducted."

\section{Acknowledgements}

This paper is part of the FReSMe project that has received funding from the European Union's Horizon 2020 research and innovation programme under grant agreement No. 727504.

\section{References}

[1] Carbon Capture and Storage - SaskPower n.d. http://www.saskpower.com/our-power-future/carbon-capture-and-storage/ (accessed December 14, 2017).

[2] CRI - Carbon Recycling International n.d. http://carbonrecycling.is/ (accessed August 30, 2018).

[3] MefCO2 (Methanol fuel from CO2) - Synthesis of methanol from captured carbon dioxide using surplus electricity. | SPIRE n.d. https://www.spire2030.eu/mefco2/ (accessed August 30, 2018).

[4] FReSMe n.d. http://www.fresme.eu/ (accessed August 31, 2018).

[5] Gazzani M, Romano MC, Manzolini G. $\mathrm{CO}_{2}$ capture in integrated steelworks by commercial-ready technologies and SEWGS process. Int J Greenh Gas Control 2015;41:249-67. doi:10.1016/j.ijggc.2015.07.012.

[6] Hansen JB, Højlund Nielsen PE. Methanol Synthesis. Handb. Heterog. Catal., Weinheim, Germany: Wiley-VCH Verlag GmbH \& Co. KGaA; 2008, p. 2920-49. doi:10.1002/9783527610044.hetcat0148.

[7] Colbertaldo P, Gómez Aláez SL, Campanari S. Zero-dimensional dynamic modeling of PEM electrolyzers. Energy Procedia 2017;142:1468-73. doi:10.1016/J.EGYPRO.2017.12.594. 